\title{
Market Impacts of Technological Change for Sorghum in Indian Near-Subsistence Agriculture
}

\author{
Jere R. Behrman and K. N. Murty
}

\begin{abstract}
Fvaluating market impacts of technological change for near - subsistence crops like sorghum in semiarid tropical India is complicated because of diversified agriculture. geographically isolated markets, and therefore feedbacks through prices, and producer-demander income links for such products. Dy namic simulatuon w ith a multicommodity market model suggest that increased sorghum productivity would have spillover effects on other markets, increase the welfare of sorghum consumers, and probably lower the sorghum price. Contrary to speculations of some experts, the output gain prohably would he greater than the pure productivity effect despite the price decline because of induced input allocations favoring sorghum production.
\end{abstract}

Key words: India, market responses, sorghum, subsistence agriculture, technological change.

The initial successes of the green revolution were the "superior" grains, like wheat and rice, grown primarily in monoculture or near monoculture in irrigated and relatively well-off areas like the Punjab and usually with most of the production traded in geographically wellintegrated markets. Emphasis subsequently has shifted to exploration of technological change for near-subsistence products like sorghum and chickpeas that are grown largely in diversified agriculture under rainfed conditions in poorer areas like semiarid tropical peninsular India, often with substantial proportions of the production consumed by the producers themselves and with the marketed

Jere R. Behrman is William R. Kenan, Jr., Professor of Econom ics, codirector of the Center for the Analysis of Developing Economies (CADE), associate of the South Asia Regional Studies Program at the University of Pennsylvania, and consultant at the Economics Program. ICRISAT. K. N. Murty is a lecturer in economics. University of Hyderabad, and for most of the period of the present study was an economist at the Economics Program. ICRISAT.

Approved as Journal Article No. 319 of the International Crops Research Institute for the Semi-Arid Tropics.

The authors wish to thank for useful comments, but not impli-

cate, H. Binswanger, J. Quizon, R. Radhakrishna, M. von Oppen,

J. Ryan, T. Walker, and the anonymous referees of this Journal.

They also would like to thank P. Parthasarathy Rao, K. V. Subba

Røo, M. Nayeemuddin, and S. Lalitha for their help in data collectins and processing.

Review was coondinated by Hans P. Binswaner, associate editor. surplus sold in geographically isolated markets. In his recent Kellogg Fiftieth Anniversary Lecture, Nerlove observed that the profession has acquired substantial information about the former type of crops, but large lacunae in our knowledge remain for the latter.

Evaluation of the impact of technological innovations on product markets is much more complicated for products like sorghum in India than for the superior grains because such analysis must recognize the added complexities of production, demand, and markets for these crops.' The existence of diversified production means that the supply/production side of the market must be modeled to allow substitution among various crops. The geographically isolated product markets mean that output expansion of a particular crop due to a technological innovation may cause the price of that crop to fall, perhaps substantially, which may discourage future output. Feedbacks through product markets, moreover, may cause changes in the prices for other products that also are characterized by geo-

\footnotetext{
I In this paper emphasis is on product markets. Though important changes also might occur in factor markets, inadequate data preclude incorporation of many of the features of fector markets. However, the sensitivity analysis below includes exploration of the importance of an alternative assumption concerning labor inartets.
} 
graphically isolated markets. Likewise, induced shifts in input usage may affect input prices that are determined in isolated markets, with feedback effects on production of all local products. Therefore, the modeling must incorporate the endogenous determination of all of the prices that reflect the isolated nature of the relevant markets. To do so, demand systems must be included that allow for substitution among the major demand categories in response to the relative price changes. The output demand systems also must incorporate endogenous income effects sincè substantial shares of the production of such crops often are consumed by the producers themselves. For the crop examined in this paper, for example, about three quarters of the production is consumed by the producers.

This paper considers the product market impacts of a hypothetical technological inno* vation for such a crop: sorghum in semiarid tropical (SAT) India. Sorghum is one of the five mandate crops of the International Crops Research Institute for the Semi-Arid Tropics (ICRISAT) located near Hyderabad in India. Research at ICRISAT, in Indian research programs like AICRPDA and ICAR, or elsewhere may lead to significant technological improvements in sorghum production. However, some experts have expressed the fear that technological innovation for sorghum in SAT India would depress sorghum prices to such an extent that farmers would shift away from sorghum production enough so that there would be little output gain. The purpose of this paper is to explore this proposition and other related market impacts of technological change for such a crop. The method employed is to simulate the impact of a hypothetical technological change in sorghum production with a market model based on supply and demand systems for SAT Indian agriculture, making explicit assumptions regarding price determination. Sensitivity analysis is undertaken to explore the impact of several critical assumptions that cannot be tested directly because of data inadequacies.

\section{The Model}

The approach of this investigation is to specify a model of the relevant SAT Indian agriculture markets and then to use this model to simulate the impacts of a hypothetical improvement in sorghum production. The major components of the model are discussed in turn.

\section{Supply}

The basic system output supply-factor demand model for one observation is represented in vector notation as ${ }^{2}$

$$
S=f\left(P^{*}, X, U\right)
$$

where $S$ is an $m$-element vector of quantities, including the output supplies of each of the $m_{s}$ commodities defined below and the input demands for each of $m_{t}$ variable inputs: $P^{*}$ is an $m_{\varphi}$-element vector of expected prices at the time of production decisions with one element corresponding to each of the first $m_{s}$ elements of $S ; X$ is an $m_{x}$-element vector including $m_{v}$ input prices and the $m_{n}$ additional nonpurchased or fixed variables such as noted below; $U$ is an $m$-element vector of stochastic terms to represent unobserved factors, one for each of the elements of $S$.

An equivalent representation of the $i$ th crop output (or input), which is approximated below, is the growth rate form:

$$
\text { (2) } \dot{S}_{1}=\sum_{j=1}^{m_{s}} E_{S_{l} p_{j} j} \dot{P}^{*}{ }_{j}+\sum_{j=1}^{m_{x}} E_{S_{l}, \lambda_{j}} \dot{X}_{j}+E_{S_{i} U_{l}} \dot{U}_{1}
$$

where the standard convention is used that a dot above a variable means the rate of change $(\dot{Z}=\partial Z / Z) ; E_{Y Z}$ is the elasticity of $Y$ with respect to $Z$; and subscripts $i$ and $j$ refer to elements in the indicated vector. Equation (2) states that the growth rate of the ith crop's output supply (or input factor demand) is a weighted average of the growth rates of all expected prices $\left(\dot{P}^{*},\right)$, all of the additional variables $\left(X_{1}\right)$, and the disturbance $\left(U_{1}\right)$. with the weights being the respective output (or input) elasticities. The elasticities incorporate the underlying technological and behavioral responses to changes in various expected prices and other variables. In general, the elasticities are not constant but depend on the overall configuration of output supplies and input demand, which in turn depend on the overall configuration of expected prices and other variables.

This study uses the careful supply "system A" estimates for SAT India by Bapna, Binswanger, and Quizon (hereafter BBQ).

\footnotetext{
3 This formulation abstracts from posesibilities like riak averion and does not inctude the impact of hicher moments on mpply.
} 
These estimates are pooled time-series (1957) 58-1973/74) cross-section (73 districts aggregated into thirteen regions in the SAT Indian states of Tamil Nadu, Karnataka, Andhra Pradesh, and Madhya Pradesh) estimates based on underlying normalized profit functions to obtain' relation (1), with expected prices represented by a distributed lag in actual prices, and with the disturbance for the $i$ th crop (input) in the th period having a variance-components structure with regional, time, and residual error components. ${ }^{3}$

In this supply system the number of output commodities $\left(m_{s}\right)$ is six: (a) sorghum (almost exclusively a food grain in India), (b) superior cereals (wheat and rice), (c) other coarse cereals (pearl millet, maize, finger millet, kudon. kutki, and other minor millets), (d) pulses (chickpea, pigeonpea, green gram, black gram, horse gram, and other pulses), (e) oilseeds (groundnuts, sesamum, castor bean, and linseeds), and $(f)$ other crops. (sugarcane, cotton, tobacco and chilies). The available data permitted empirical incorporation of only two $\left(m_{r}\right)$ purchased (or purchasable) variable inputs: $(a)$ fertilizers (as measured in tons of nutrients $\mathrm{N}, \mathrm{P}_{2} \mathrm{O}_{3}$ and $\mathrm{K}_{2} \mathrm{O}$ ) and $(b)$ labor. $^{4}$ Five additional variables $\left(m_{a}\right)$ also were included: $(a)$ rainfall, $(b)$ road density in length of roads per unit area, $(c)$ irrigation as proportion of cropped area, (d) market density per unit area, and (e) high-yielding varieties as proportion of total cropped area.

Table 1 summarizes the implied price elasticities at the sample means. The simulations to be discussed use these elasticities under the assumption that the elasticities in relation (2) are approximately constant. The elasticities imply some interesting partial-equilibrium features. The cwn-price elasticities range from 0.16 to 0.87 , with that for sorghum equal to 0.43 ; such values indicate fairly substantial price responsiveness in this relatively poor agricultural area. Several of the cross-crop elasticities also are fairly large with absolute magnitudes on the order of 0.2 to 0.3 , which sug-

\footnotetext{
S The included states account for the following percentages of Indian output and acreage of the major crops considered in this study: wheat $(10.8,17.5)$, nce $(15.6,14.1)$, sorghum $(36.7,42.0)$, other cereals $(30.2,22.4)$, pulses $(24.3,31.0)$, oil seeds $(37.4,35.0)$, and other crops (27.1, 28.2). In regard to the lag structure, after experiments with various alternatives, BBQ adopted a uniform distributed-lag specification for all expected crop prices with a weight of 0.71 on the actual price lageed one year and a weight of 0.29 on the actual price lagged two years.

4 Labor input data were not available, but the effect of labor market conditions was incorpornted by including the daily male wee rales for standard eisht-bour davs.
}

gests important intrasystem substitution in production.

\section{Demand}

The basic demand or expenditure system for one observation can be represented in vector notation as

$$
D=g\left(P^{\prime \prime}, Y, \eta\right)
$$

where $D$ is a n-element vector of quantities demanded for the commodities defined helow: $P^{d}$ is a $n$-element vector of prices faced by consumers, with one element corresponding to each element of $D ; Y$ is total expenditure: and $l$ is a 11 -element vector of stochasic terms to represent unobserved factors, one tor each of the elements of $D$. An equivalent representation for the $i$ th commodity demand, which is approximated below, is the growth rate form.

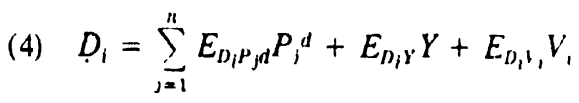

where the conventions defined for relatior: (2) apply. Relation (4) states that the growth rate of the demand for the ith commodity is a weighted average of the growth rates of all prices faced by demanders $\left(\dot{P}_{j}^{d}\right)$, of expenditure $(\dot{Y})$, and of the disturbance $\left(V_{1}\right)$, with the weights being the respective demand elas ticities. These elasticities incorporate the underlying behavioral responses and the aggregation across individual households. In general the elasticities are not constant but depend upon the overall configuration of market prices, expenditures, and the distribution of purchasing power.

This study uses demand system estimates for low-income rural Indians from the carefu! study by Murty and Radhakrishna hereafter MR). MR utilize the Nasse generalization of the linear expenditure system for relation (3), which allows nonadditivity in the underlying utility function.' In order to overcome the linear expenditure effects implied by this model, they subdivide the sample into five reai expenditure groups for rural areas and five for urban areas. They allow for cross-equation correlations in the elements of the disturbance vector $(V)$ by using a generalized least-squares estimator. Under these assumptions, MR ob-

\footnotetext{
To satisfy the convexity conditions $\mathrm{MR}$ impose the restrictions that noafood proups are additively separable, thus reducine this ont of the model to a binear expenditure, system.
} 


\begin{tabular}{|c|c|c|c|c|c|c|}
\hline SI'T & $21 \cdot 1$ & $b 2 \cdot 1$ & $69^{\circ} 0$ & $£ 6^{\circ} 0$ & 10.1 & 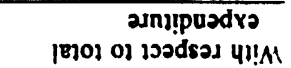 \\
\hline 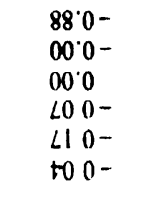 & $\begin{array}{l}100- \\
290- \\
500 \\
+10- \\
280- \\
800-\end{array}$ & $\begin{array}{l}50.0- \\
60.0 \\
66.0- \\
80^{\circ} 0^{-} \\
61^{\circ} 0^{-} \\
50.0-\end{array}$ & $\begin{array}{l}900- \\
20.0- \\
100- \\
i E^{\circ} 1- \\
950 \\
510\end{array}$ & $\begin{array}{l}80.0- \\
20.0- \\
10.0- \\
610 \\
02.1- \\
0 \div 0\end{array}$ & $\begin{array}{l}600- \\
80.0- \\
100- \\
16.0 \\
88.0 \\
66.1-\end{array}$ & 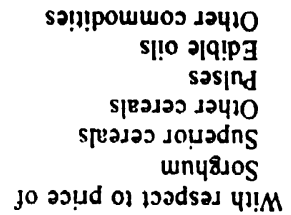 \\
\hline 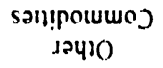 & $\begin{array}{l}\text { sio } \\
\text { गQ193 }\end{array}$ & sasjnd & $\begin{array}{l}\text { Jayio } \\
\text { spajas }\end{array}$ & $\begin{array}{l}\text { poljadins } \\
\text { spalaj }\end{array}$ & wnytios & \\
\hline
\end{tabular}

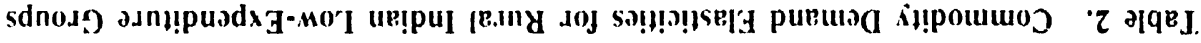

JoJ luejodu! s! 'suo!jejas puewap [enp!s!pu! Jo peajsu! 'waisís puewap e su!sn uosead s!4l

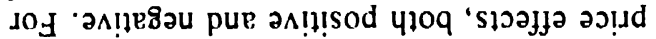

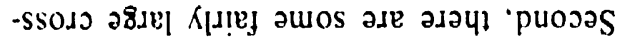

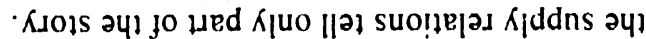

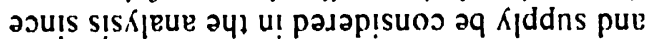

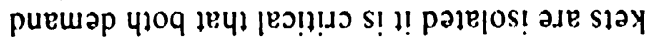

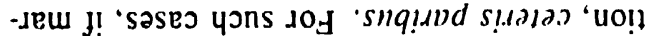

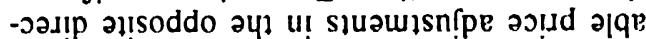

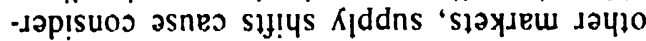

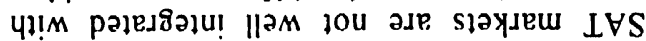

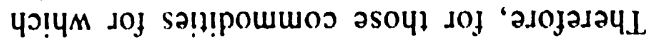
- ìluyu! as!nesau wody Jef ade inq unysuos

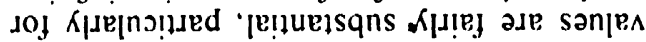

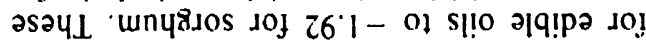

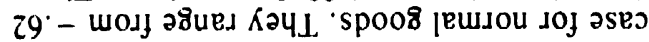

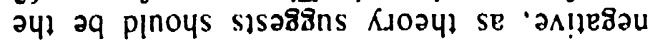

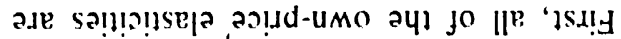

sumaned suimsanol

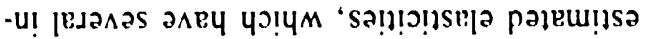

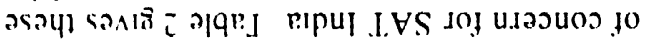
s.

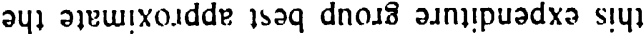

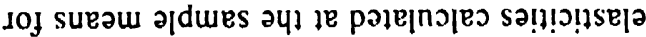

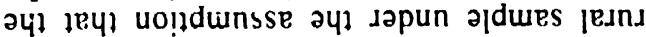

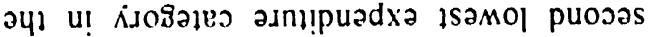

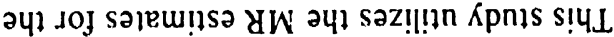
sய21!

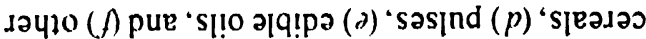

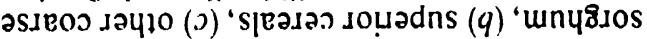

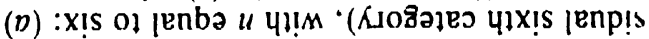

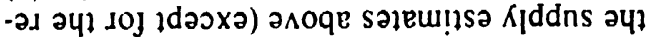

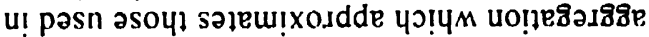
Jo

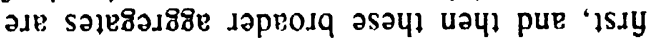

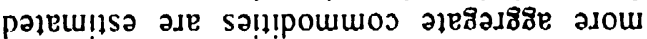
Jof suonenba pueuap jo sualsरs чग!५м U!

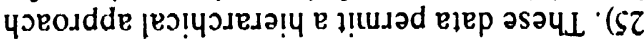

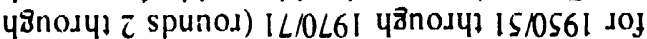

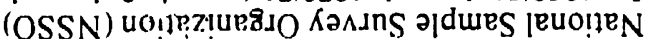

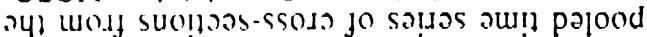

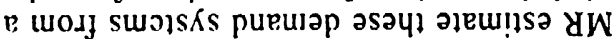

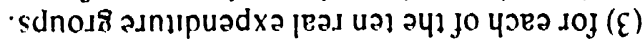
u(!)

suoisipuos

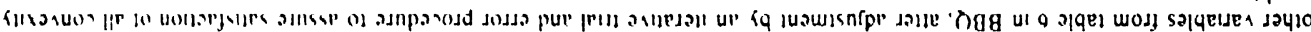
I0) ,

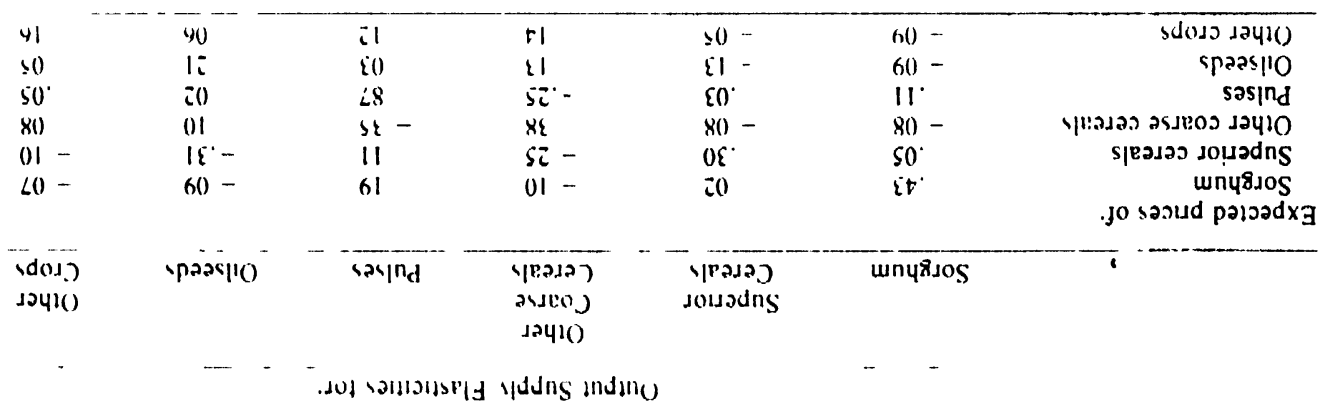


analysis of various scenarios. For example, a $10 \%$ increase in the price of sorghum implies increases of $2 \%$ and $1.5 \%$, respectively. in quantities demanded of superior cereals and of other coarse cereals, and decreases of 0 to 17 for edible oils. pulses, and all other commodities.

Third, the expenditure elasticities vary somewhat with those for other coarse cereals (.69) relatively irresponsıve. those for superior cereals (.93) and sorghum (1.01) intermediate, and those for the other categories somew hat higher $(1.12$ to 1.24). Thus, as income and expenditure increase. cotems parthus, there is the well-hnown shift in expenditure shates aw d) from other codrse cereals and. 10 a leser extent, from superior cereals and sorghum to pulses, edible oils, and other commodities.

\section{The Production Equals Absorption Identity}

For the ith commodity in SAT agriculture the total supply is SAT production $\left(S_{1}\right)$ plus net imports into SAT $\left(M_{1}\right){ }^{6}$ The total absorption includes demands for current human consumption $\left(D_{1}\right)$, for current livestock consumption $\left(L_{i}\right)$, for seed reserves $\left(R_{i}\right)$, and for changes in inventories held by producers $\left(\Delta l_{i}^{p}\right)$, consumers $\left(\Delta J_{i}^{c}\right)$, market wholesalers and retailers $\left(\Delta_{1}^{\prime \prime}\right)$ and public authorities $\left(\Delta_{1}{ }^{\rho}\right)$. In addition, there is significant wastage $\left(W_{1}\right)$, including spoilage and loss to insects and other animals. Total supply equals total absorption:

$$
\text { (5) } \begin{aligned}
S_{i}+M_{1}=D_{1} & +L_{i}+R_{i}+\Delta V_{i}^{p} \\
& +\Delta V_{i}{ }^{c}+\Delta V_{i}^{m}+\Delta l_{1}^{p}+W_{i} .
\end{aligned}
$$

In principle, all of the components of supply and absorption indicated in relation (5) may be responsive to actual and/or expected prices of SAT commodities. If their responses differ, the composition of both supply and demand may change as prices (or expected prices) change.

In practice, unfortunately, data are not available with which to estimate the market responsiveness of most of these components. Therefore, this study assumes for the three crops for which the SAT markets are not well integrated with other markets (i.e., sorghum, other cereals, and pulses) ${ }^{7}$ that the sum of net

\footnotetext{
- Net imports, of course, are negative if exports exceed imports.
}

'In these cases, for the most part, net trade between SAT India exports, livestock use, seed reserves, producer stock changes, and wastage in proportional to supply:

$$
a_{1} S_{1}=L_{1}+R_{1}+I_{1}^{\prime \prime}+W_{1}-M_{1} .
$$

Likewise, for these commodity groups, the sum of other (i.e.. nonproducer) inventory changes is assumed to be proportional to demand:

$$
h D-y_{i}^{\prime}+J^{\prime \prime}+y_{1}^{\prime \prime}
$$

Under these assumptions, ielation (5) mas be rewritten as

$\begin{array}{rr}(5 \mathrm{~A}) & (1-(11.5,-11 \cdot b 1 l) \\ (5 \mathrm{~B}) & .5,1) \cdot\left(x_{1}\right.\end{array}$

where

$$
\left.\left.\alpha_{1}=\cdot\left(1+b_{1}\right) / 1\right)-a_{1}\right) .
$$

Relation (5B) can be utilized with relation (2) substituted in the left side and with relation (4) substituted for the first term in the right side, which ties the production equals absorption identity of relation (5) directly back to the discussion above about supply and demand systems.

At the other extreme are most of the other commodity supplies or demands in the model, in which SAT production or consumption is a small proportion of total Indian quantities and for which markets are relatively well-integrated geographically. In these cases net SAT imports are large and variable compared with SAT production. Therefore prices are assumed to be set in the larger Indian markel outside of SAT or by government policies (e.g., fertilizers) with behavior in SAT responding to such prices. The commodities in this category include superior cereals, the other-crop supply category, fertilizer, and other-commodity demand category.

Finally one intermediate case between these extremes is posited. For oilseeds-edible oils SAT production is a fairly large share of the Indian total (about $45 \%$ in 1978) and the market is fairly well integrated geographically. In this case, therefore, an intermediate assumption is made between the extremes of prices being determined completely within SAT (as for sorghum, other coarse cereals, and pulses) and prices being determined entirely uutside of SAT (as for all remaining categories). The 
intermediate assumption is that the price is an inverse function of SAT quantity produced along a fairly flat price-quantity locus that reflects explicitly the SAT production share and the total Indian demand elasticities and the non-SAT supply elasticity. By differentuation of the identity that SAT plus non-SAT supply equals total Indian demand:

$$
E_{Y P}=\frac{D^{r}}{X} E_{l, r_{p}}-\frac{S^{r}}{v} E_{s r_{p}}
$$

where the superscript $r$ refers to the rest of India and $X$ is exports from SAT to the rest of India.

\section{Supply- and De'mund-Pro' Re'atums}

Prices are determined outside of the model for superior grains, the other-crops supply category, fertilizer, labor, and the other-commodities demand category. For the commodities on the supply side, in addition, there are expected prices $\left(P^{*}\right)$ based on actual supply prices $\left(P_{2}\right)$ as indicated in note $(3)$ and prices which consumers pay on the demand side $\left(P_{i}^{d}\right)$. The prices which consumers pay differ from those which farmers receive due to transportation, marketing, and processing costs $\left(m_{i}\right)$, which differ from crop to crop:

$$
P_{i}^{d}=m_{i} P_{i}
$$

so that

$$
P_{1}{ }^{d}=\dot{P}_{i}+m_{i}
$$

The prices of sorghum, other grains, and pulses also are assumed to adjust within each year to clear approximately the individual markets.

\section{Producer Revenue-Demander Expenditure Linkage}

A characteristic which distinguishes SAT Indian near-subsistence agriculture from more commercialized agriculture is that a substantial part of production is consumed by the farmers themselves. This implies an additional. link between supply and demand beyond those through market prices since the total expenditure of demanders depends in considerable part on the revenues of producers. To capture this link, total expenditure in the demand system is posited to depend on the weighted sum of the value of SAT production of the six supply commodities' in the BBQ supply system $\left(\sum_{i=1}^{6} S_{1} P_{1}\right)$ minus expenditures on fertilizer $\left(S_{7} P_{7}\right)$ plus other net expenditures $\left(\gamma_{10}\right)$ which are independent of price and quantuty movements for the commodities of concern: ${ }^{8}$

$$
Y=c^{\prime}\left(\sum_{i=1}^{6} S_{1} P_{1}-S_{7} P_{7}\right)+Y_{0} .
$$

The components of $Y_{1}$ may include some com-

generation and savings activity. But a substantial proportion of SAT economic actuvity may be related to the value of production of the farm commodities through the impact on related service and transport activities, which implies a value of "' greater than one. On the other hand, the first right-side expression in relation (10) is an overstatement of expenditure from SAT agricultural production to the extent that other nonfertilizer inputs and savings are not deducted from the gross value of production, which implies a value ot $c$ below one, ceteris paribus. This study assumes that the net impact of these considerations can be represented at the margin by the following approximation:

$$
\dot{Y}=c \dot{Z}+Y_{o}
$$

where

$$
Z=\sum_{i=1}^{6} P_{i} S_{1}-P_{7} S_{7} \text { and } c=0.6 .9
$$

\section{The Base Simulation}

The reference point for the simulations of the next sections is a base simulation in which all endogenous variables are solution values given the actual values for exogenous variables and in which all of the stochastic terms have their expected values of zero. This is a more useful reference point than actual values for the endogenous variables would be because it makes clear the systematic impact of hypothesized changes without confusing effects of stochastic terms.

\footnotetext{
- Note that all production is valued at market pnces even though some of it is consumed on the farm without entering the market. The question of whether all or only the marketed portion of production should be valued at market prices underlay a debate between Krishm and Behrman of some years apo repanding indirect measures of the price elasticity of the marteted surplus.

- Estimatine the empirical value of $c$ is not easy because of

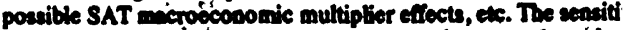

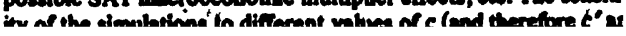


In this base simulation, $\dot{\alpha}_{1}$ and $\dot{m}_{2}$ are assumed to be zero in relations (SB) and (9A), respectively. The former assumption is equivalent to assuming that the combined impact of net exports, livestock use, seed reserves, wastage and stock change is constant [i.e., $\left(1+b_{i}\right) /\left(1-a_{i}\right)$ is constant] for each crop over time. The latter assumption implies that transportation, marketing and processing costs are constant for each crop over time. These two assumptions are made for the base simulation because inadequate data preclude direct estimates of possible changes over time in $\alpha_{1}$ and $m_{1}$. Below, however, there is consideration of the impact on the basic simulation of technological change in sorghum if these assumptions are modified for this crop.

The base simulation is a ten-year dynamic simulation for 1969-70 through 1978-79 in which, within the simulation period, simulated values of lagged endogenous variables are used instead of actual values. These lagged simulated values are one of the two major mechanisms which link impacts of the hypothetical exogenous change in sorghum technology across periods in a dynamic fashion through the lagged values to which the growth rates in relations (2) and (4) are applied to obtain the levels of endogenous variables for the current simulation period. The other major dynamic mechanism is through the endogenous expected price generation process. The use of a decade simulation period allows substantial time for the dynamic effects of initial exogenous changes to work their way through the system. The use of a long simulation period also permits exploration of whether or not there is error buildup in the model. On the other hand, a decade may be a somewhat long period for the maintained hypothesis of no structural changes other than that posited for sorghum productivity, so most results in this paper also are presented for a shorter period of five or six years.

The first three columns in table 3 give some summary measures of the goodness of fit of the base simulation: mean absolute percentage errors (MAPE) for 1969-73 and for 1969-78 and root mean percentage errors (RMPE) for 1969-78.

The goodness-of-fit statistics for the entire decade in table 3 suggest that the model traces better the actual experience for SAT quantities supplied than for SAT prices (though pulses are an exception to this pattern). This is riod for the relevant commodities. ${ }^{10}$ supplies are completely price inelastic, so all of the adjustment to achieve short-run equilibrium must be in prices along the demand curve to the recursively set quantities supplied.

The goodness-of-fit statistics also are relatively high for superior-cereals quantity demanded. They are relatively small for the quantity demanded for the other-items category and total consumer expenditure. The low value for total consumer expenditure is due to a combination of some of the errors in the components of this variable cancelling out in the constructed aggregate (particularly high prices for low quantities suppled and vice versa) and of there being an exugenous component $\left(Y_{0}\right)$ in relation (10). The low error for the other-consumer-demand components reflects the small error in total expenditure in combination with the exogenously fixed value of the other major determinant of this demand variable-the own price (given the small cross-price elasticities for this category in table 2).

The MAPE and RMPE also are relatively large in comparison with those reported in many other studies. This may reflect several factors. First, the dynamic simulation period of a decade is fairly long and there is significant error buildup. This can be seen in that the MAPEs generally are smaller (and often substantially so) for the first five years than for the whole decade (compare columns 1 and 2 in table 3). $"$ In other words, as is almost always the case for such models, there is more success in tracing out experience in the short and medium runs than for the longer run. This is particularly the case for the sorghum price.

Though the MAPEs for the first quinquennium are lower than for the decade. they still are relatively large. This may be because of the great volatility of SAT agriculture despite the attempt to incorporate weather conditions in the supply estimates (i.e., $U$ is relatively large in relation 1). To the extent that this is the case, the base simulation just reflects the well-known environmental variability in SAT agriculture and the difficulty of summarizing that dimension of reality in manageable weather indices for econometric estimates.

Another contributing factor may be that the systems estimates do not assume that the 
Table 3. Summary Measures of Percentage Errors in Base Simulations and Percentage Deviations from Base Simulations for Simulated Scenario with Improved Sorghum Productivity

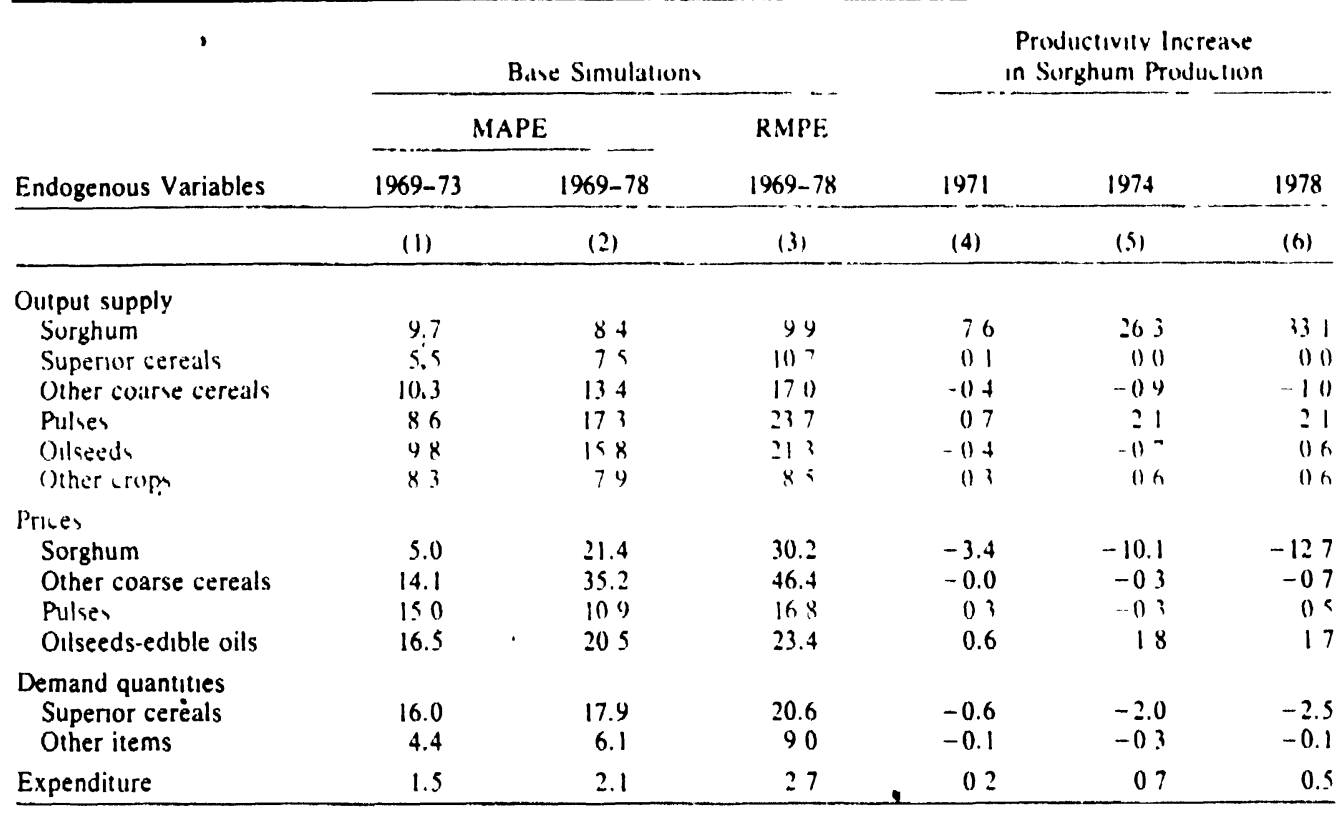

Note: Base simulation, MAPE, and RMPE are defined and discussed in the second section The scenarios with improved sorghum productivity are defined and discussed in the third section This table gives percentage deviations from the base simulation for this scenano.

mean error for each endogenous variable is zero over the estimation period (as do ordinary least squares single-equation estimates), so in some cases the base simulated values are systematically too high or too low. To the extent that this possible system feature underlies the relatively large errors, some questions are raised about the stochastic specification of the system estimates and the models may under (over) estimate systematically some endogenous variables. Nevertheless, the model may serve well (and possibly better than single-equation estimates which would trace the sample experience better, but not capture the system features as well) for exploring the impact of hypothesized exogenous changes.

In addition to goodness-of-fit measures based on errors, it is useful to ask how well the model traces turning points in SAT Indian agricultural experience over the simulation decade. Examination of the individual observations (which are not presented because of space limitations) suggests that the summary answer to this question is: fairly well, especially given the great volatility in SAT Indian agriculture. There are some failures, but these tend to be concentrated in the latter half of the simulation period after there is more substantial error buildup. All in all, there is fairly considerable success in identifying turning points.

\section{Basic Simulation of Productivity Increase in Sorghum}

For the exploration of the product market impacts of technological improvements in sorghum production, an S-shaped pattem of percentage increases in productivity is assumed because that is the typical pattern of the adoption of innovations in SAT Indian agriculture as in most other agriculture (see Walker and Singh). The exact pattern of assumed annual increases is $0.5 \%, 1.5 \%, 3.5 \%, 4.5 \%, 5.0 \%$, $4.5 \%, 3.5 \%, 1.5 \%$, and $0.5 \%$ during $1969-77$, respectively. The accumulation of these changes results in an upward shift in productivity of $25 \%$ for the ninth year and thereafter.

To simulate the impacts of a $T \%$ increase in the productivity of sorghum in any year, the combined imnact of what can be considered 
tion increases $T \%$ with the same use of inputs. (b) Because of the productivity increase in sorghum, there is a reallocation of inputs among all of the crops. If the actual output and input prices were constant, this effect would be equivalent to the impact of a $T \%$ increase in the price of sorghum (including all of the effects through the cross elasticities).$^{12}(c) \mathrm{Be}$ cause of the resulting expansion of sorghum output and induced changes in other outputs. sorghum and other output prices adjust, with the standard impact on all outputs through the price elasticities. The total.impact is the combination of these three effects, with the negative third one partially offsetting the positive first tho. Further complications, of course. are introduced by the lag structure in responses due to the price expectation formation process.

The basic simulation explores the impacts of this hypothetical technological improvement in sorghum production by imposing it onto the base simulation of the previous section. Columns $4-6$ in table 3 present the resulting impacts as indicated by the percentage deviations induced from the otherwise identical base simulation for 1971, 1974, and 1978 (i.e., years two, six, and ten of the simulation period) because of the sorghum productivity change. The magnitudes of the impacts of the assumed productivity increase in sorghum change over the decade because of the assumed pattern of initially increasing and subsequently decreasing productivity growth. But the general implications are the same over time.

First of all, there is the anticipated negative impact on the sorghum price in order to absorb within SAT India the increased sorghum production. By the sixth year of the simulation the price decline is $10.1 \%$ (for a production increase of $26.3 \%$ ). By the tenth year it is $12.7 \%$ (for a production increase of $33.1 \%$ ). These price declines somewhat discourage sorghum production. Therefore, output does not increase as much as it would were there no induced downward sorghum price movement as would be the case were the SAT Indian sorghum market well integrated into a much larger market.

Second, sorghum output, nevertheless, increases more than sorghum productivity. In

\footnotetext{
12 The authors thank H. Binswanger for most useful discussions on bow to conduct these simulations, in paricular regarding the enonnd mifom
}

the sixth year surghum output is $26.3 \%$ above the base simulation path even though produc. tivity is only $19.5 \%$ above the base path. In the tenth year sorghum output is $33.1 \%$ above the base simulation path though productivity is $25 \%$ above the base path. The larger increases in output than in productivity despite the sorghum price declines reflect that the second effect noted above reinforces the direct pure productivity effect more than the third negative price effect offsets it. This is in sharp contrast to frequent speculations that there might be little output gain due to the output fall in response to the price decline. On the average, sorghum producers receive greater gross revenues since the production increase in much larger than the price decline. But the impact of any productivity improvement is not likely to affect all farms equally because of differences in land quality, water control. management capabilities, etc. Those sorghum farmers who experience little or no sorghum productivity increase, in fact, are worse off because of the lowered sorghum price.

Third, the larger sorghum production and lower sorghum price means that Indian SAT consumers of sorghum are undoubtedly better off due to this productivity change. Since sorghum constitutes a higher share of the budget of poorer individuals (see MR), these benefits accrue relatively more to the poorer members of society.

Fourth, even though the systemic effects are relatively weak for sorghum (in the sense that the cross-price elasticities in tables 1 and 2 are small as compared, for example, to those for superior cereals), there are some impacts on other commodities at least of the magnitude of $1 \%$ after several years. Because of the lower sorghum price, for example. pulses substitute somewhat for sorghum, vilseeds, and other crops in production and sorghum substitutes somewhat for superior cereals and other items in consumption-which lowers net imports of superior cereals and increases the net imports and the prices of edible oils. None of these effects is all that large, however.

\section{Sensitivity Analysis of Some Critical Assumptions}

The model used in this study incorporates a number of complexities such as the systems nature of supply and demand, varying degrees of market inteeration between SAT India and 
the rest of India, and feedbacks through product prices and expenditure of demanders. Nevertheless, because of data inadequacies, a number of simplifying assumptions are made for the basic simulation of the impacts of technological change in sorghum.

This section explores the sensitivity of the results to modifications in some of these assumptions. Table 4 gives percentage deviations from the base simulation for 1971 and 1974 for six simulations, each of which is identical to the basic simulation with technological change in sorghum productivity discussed in the previous section except for one additional change. The additional change in the first two of these simulations is that $\alpha_{1}$ for sorghum in relation $(5 \mathrm{~A})$ is posited to be $-2 \%$ or $+2 \%$ in each year, respectively. That is, the combined effect for sorghum of net exports. livestock use, seed reserves, wastage, and all stock additions changes systematically over the simulation period because of the sorghum productivity change. In the third and fourth of these simulations additional changes are that $\dot{m}$, for sorghum in relation (9A) is assumed to be $-2 \%$ or $+2 \%$ in each year, respectively. These changes imply stochastic induced variations in transportation, marketing, and processing costs that separate supply from demand prices. The fifth simulation considers an increase in the wage to a level $2 \%$ above the base simulation in each year to be induced by the technological development for sorghum. The sixth simulation hypothesizes that the producer revenue-demand expenditure link in relation $(10 \mathrm{~A})$ is stronger with ( equal to 0.8 instead of 0.6 . In all cases the changes are assumed to persist throughout the simulation period in order to provide a fairly strong test of the robustness of the results in table 3

The changes in these sensitivity simulations from the basic sımulation in table 3 are in the directions that one would anticipate. lesser absorption of sorghum by net exports, livestuck use, seed reserves, wastage, and stock changes in the first of these simulations. for example, lowers the expansion of sorghum production (e.g. from a $26.3 \%$ increase to a $24.1 \%$ increase in the sixth vear) and increases the sorghum price decline (from $-10.1 \%$ to $-14.7 \%$ in the same year six). The increased transportation-marketing-processing costs in the fourth simulation reduce further sorghum farm prices (from $-10.1 \%$ to $-18.6 \%$ in year six), which moderates the expansion in sorghum output (from 26.3\% to 22.1\% in year six). The increased wages in sımulation five reduce slightly the increment in sorghum production (from $26.3 \%$ to $25.6 \%$ in year six) and the fall in sorghum prices (from $-10.1 \%$ to

Table 4. Sensitivity Analysis of Simulation of Impact of Improved Productivity for SAT India

\begin{tabular}{|c|c|c|c|c|c|c|c|c|c|c|c|c|}
\hline \multirow{3}{*}{$\begin{array}{l}\text { Indogenous } \\
\text { Iariables }\end{array}$} & \multicolumn{4}{|c|}{$\begin{array}{l}\text { Change in Sorghum Net Exports, } \\
\text { Livestock Use. Seed Reserves, } \\
\text { Wastage. and Stocks in Relation } \\
\text { (SA) in Each Year }\end{array}$} & \multicolumn{4}{|c|}{$\begin{array}{l}\text { Change in Surghum Tiansportation. } \\
\text { Marketing-Processing Costs in } \\
\text { Relalion }(9+1) \text { in bach rear }\end{array}$} & \multirow{2}{*}{\multicolumn{2}{|c|}{$\begin{array}{l}\text { (s) Hage } \\
\text { Incredsed w } \\
\therefore \text { in } \\
\text { I wh ieat }\end{array}$}} & \multirow{2}{*}{\multicolumn{2}{|c|}{ 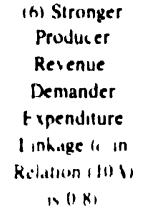 }} \\
\hline & \multirow{2}{*}{\multicolumn{2}{|c|}{ 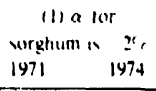 }} & \multicolumn{2}{|c|}{$\begin{array}{c}121<x \text { tor } \\
\text { wrghum w } 24\end{array}$} & \multicolumn{2}{|c|}{$\begin{array}{l}\text { lism for } \\
\text { sorghum : }=\end{array}$} & \multicolumn{2}{|c|}{$\begin{array}{c}\text { (4)" lin } \\
\text { sorghum } 42 \%\end{array}$} & & & & \\
\hline & & & 1971 & 1974 & $197 \mid$ & $1 y^{\top}+$ & 1971 & 1974 & $|y\rangle \mid$ & $1 y^{-}:$ & $\left|y^{-1}\right|$ & $1 y^{2}+$ \\
\hline \multicolumn{13}{|l|}{ Uutput supply } \\
\hline Supenor cereals & 00 & 00 & 01 & 01 & 01 & 01 & 00 & 00 & -01 & 1): & -11 & 1? \\
\hline surghum & 68 & 241 & 83 & $2 \times 6$ & 90 & 307 & 61 & $\because 21$ & by & $24 \mathrm{n}$ & ys & $2 x y$ \\
\hline \multicolumn{13}{|l|}{ Other coarse } \\
\hline cereals & -03 & -08 & -05 & -10 & 05 & 11 & -03 & -07 & -07 & $-1:$ & 07 & -02 \\
\hline Pulses & 06 & 16 & 09 & 27 & 11 & $3:$ & 04 & 12 & 03 & 16 & 67 & SR \\
\hline Olsceds & -02 & 04 & -05 & 10 & $0 \mathrm{~h}$ & 11 & 01 & 01 & 01 & $0 n$ & 18 & 13 \\
\hline Otter srops & -02 & -04 & -04 & -08 & $0+$ & -10 & 01 & 02 & -04 & $0^{-}$ & 111 & $11 \mathrm{~h}$ \\
\hline \multicolumn{13}{|l|}{ farm pnces } \\
\hline Surghum & -61 & $-1+7$ & -08 & -54 & 18 & -09 & $-8 s$ & -186 & -32 & $-y y$ & 11 & १ I \\
\hline \multicolumn{13}{|l|}{ Other coarse } \\
\hline cereals & -05 & -12 & 04 & 06 & 08 & 14 & -09 & -19 & $0 ?$ & -01 & $5:$ & 57 \\
\hline $\begin{array}{l}\text { Pulses } \\
\text { Onlseeds-edible }\end{array}$ & -0.2 & -01 & -04 & -0.5 & $-0 s$ & -06 & -01 & 0.1 & 01 & 01 & 73 & 86 \\
\hline ols & 0.6 & 1.6 & 0.6 & 2.0 & 0.7 & 22 & 06 & 15 & 0.5 & 16 & 77 & 102 \\
\hline \multicolumn{13}{|l|}{ Demand quantilies } \\
\hline Superior cereals & -1.4 & -3.7 & 03 & -0.1 & 10 & 16 & -2.1 & -5.3 & -0.5 & -1.9 & 11.3 & 11.9 \\
\hline Otber irems & 0.3 & 0.5 & -0.4 & -1.2 & -0.8 & -2.0 & 0.7 & 1.2 & -0.1 & -0.3 & 11.4 & 12.5 \\
\hline Expeadiaure & 0.0 & 0.3 & 0.4 & 1.1 & 0.5 & 1.5 & -0.1 & -0.1 & 0.1 & 0.6 & 110 & 12.8 \\
\hline
\end{tabular}


$-9.9 \%)$. The strengthened producer revenue-demander expenditure linkage in simulation six intreases sorghum demand and output (from $26.3 \%$ to $28.9 \%$ in year six) and lessens the decline in sorghum prices (from $-10.1 \%$ to $-5.1 \%$ in year six). Of course, for all of these simulations there also are small changes in supplies, demands, and prices for the other products because of the systemic nature of supply and demand.

The magnitudes of the additional changes are quite small for the wage increases and the increased link between producer revenues and demander expenditure, even when such changes persist over a number of years. The magnitudes are larger for the changes in the combined effect of net exports, livestock use, seed reserves, wastage, and stock changes $\left(\underline{\alpha}_{1}\right)$ for sorghum in simulations one and two and even larger for changes in the transportation-marketing-processing costs $\left(\dot{m}_{i}\right)$ in simulations three and four. In simulation three, for example, the persistent reduction in the transportation-marketing-processing costs results in a sorghum farm price decline of about $1 \%$ in contrast to a decline of $10 \%$ or more after six years in the basic simulation of the previous section.

But the exogenous additional changes explored in this section are quite considerable when maintained over a number of years. It seems unlikely that the basic simulation in table 3 is based on a model that is systematically misspecified by as much as is assumed in table 4. Therefore, with a caveat regarding the first two implications discussed with regard to table 3 (i.e., the fall in sorghum price and a sorghum output increase exceeding the sorghum productivity increase) in the unlikely case that transportation-marketing-processing costs fall persistently as much as in simulation 3 in table 4, the conclusion of this section is that the basic thrust of the results in table 3 seem quite robust to any likely probable degree of misspecification.

\section{Summary}

This paper has helped to fill the lacunae that Nerlove noted regarding the market impacts of technological change for near-subsistence products that are grown largely in diversified agriculture in poorer regions with geographically isolated markets and therefore price and income feedbacks by examining the case of sorghum in SAT India. The simulation results seem quite robust to likely orders of mag. nitude of persistent misspecification in the simulation model. The simulations suggest that adopted technological developments to increase sorghum productivity would have spillover effects on other markets, increase the welfare of Indian SAT consumers of sorghum. and probably lower the sorghum price. In contrast to the speculations of some, however, the sorghum price decline would not be so large as to discourage much sorghum output. To the contrary. output gain would be likely to exceed the pure technological productivity effect because of input reallocations that would more than offset the negative effect on supply of sorghum price declines.

\section{[Received August 1983; final revision received Aligust 1984.]}

\section{References}

Bapna, S. L., H. P. Binswanger, J. B. Quizon. ". Systems of Output Supply and Factor Demand Equations for Semi-Arid Tropical India." Mimeographed. Washington DC: DEDERD, World Bank. 1981.

Behrman, J. R. "Price Elasticity of the Marketed Surplus of a Subsistence Crop." J. Farm Econ. 48(1966): 875-93.

Krishna, R. "A Note on the Elasticity of the Marketable Surplus of a Subsistence Crop." Indian J. Agr. Econ. 17(1962): 79-84.

Murty, K. N., and R. Radhakrishna. “Agricultural Prices, Income Distribution and Demand Patterns in a Low Income Country." Computer dpplta utuens fion Fond Production and Agricultural Ensumesing. ed. K. E Kalman and J. Martinez, pp. 155-73. Amsterdam: North-Holland Publishing Co.. 1982.

Nasse, P. H. "Analyses des Effects de Substitution dans un System Complete de Function de Demands." A 1 nales de I' Insee S(1970):81-110.

Nerlove, Marc. "The Dynamics of Supply: Retrospect and Prospect." Amer. J. Agr. Econ. 61(1979):874-88.

Raju. V. T., and M. von Oppen. Market Channels for Selected Crops in Se'mi-Arid Trupical India. Patancheru, India: ICRISAT Econ. Program Progress Rep. No. 16, 1980.

Walker, T. S., and R. P. Singh. New Seeds of Change in Dryland Research. Patancheru, India: ICRISAT Econ. Program Pub. No. 190, 1983. 